presence of raw, bleeding sores on the cutaneous as well as the mucous surface of the labia (see annexed Fig.). The temperature of the animals was not affected, and their general health appeared to be practically undisturbed.

Raw, ulcerating sores were still present inside the sheath of one of the rams, but the eruption on the upper lip of the other one appeared to be healing.

As the rams were marked with colour on the breast and between the fore legs, it was possible to determine which ewes had been tupped, and it was thus ascertained that one or two of them had contracted the disease although they had not been served by either ram. It may be observed that the ewes had been docked very close, and that the stump of tail left was quite insufficient to cover the vulva. The ewes were much tormented with flies at the time, and it appears to be possible either that some of them were thus infected, or that those which had not been tupped were infected by the disease on the nose of one of the rams.

The affected ewes were isolated, and the sores were dressed with mild antiseptics. Latterly, I dressed the lesions on the vulva with iodoform ointment. Under this treatment all the affected animals gradually recovered.

\title{
A CONTAGIOUS DISEASE OF THE GENERATIVE ORGANS IN SHEEP.
}

\section{By J. M'Fadyean, Royal Veterinary College, London.}

HAVING had the opportunity to see the animals that were affected in the peculiar outbreak described by Mr Flook in the preceding article, I am induced to publish the notes of another outbreak of the same kind which had previously come under my notice.

Towards the end of September I 896 it was reported to me that a peculiar disease had made its appearance among a flock of ewes in the county of Suffolk, and on the 29 th of that month a visit was made to the farm in question. It was then found that twelve ewes of the flock were all affected as follows: The labia of the vulva were intensely inflamed, swollen, tense, and painful. The lining membrane of the vulva showed inflammatory congestion, and in some cases ulcers were present either on the outside or the inside of the labia. There was a slight purulent discharye from the genital passages.

The explanation of the outbreak which naturally suggested itself was that the ewes must have been infected by a ram suffering from the same complaint. Unfortunately, it could not be ascertained whether that surmise was correct or not, as the ram which had been with the ewes was a hired one, and it had been returned to its owner six days previously. It was not even known with certainty that the whole of the twelve affected ewes had been served by this ram; he had had access to ten of them, but he had not been with the other two to the knowledge of the shepherd.

With a view to future experiments, pledgets of sterilised cotton wool were rubbed over some of the lesions so as to collact a little of the discharge, and on the following day one of these.pledgets was 
inserted into the vulva of a yearling ewe at the Royal Veterinary College. Another pledget was introduced within the sheath of a wether, and a third was inserted in the vulva of a cow. An hour afterwards the piece of cotton wool was found to have dropped out of the vulva of the ewe, and the plugs were then removed from the cow and the wether.

This procedure had entirely negative results in the ewe and the cow, but on 2nd October the sheath of the wether was found to be slightly swollen around the orifice. On the following day the swelling had increased, and a brownish crust or scab had formed on the skin close to the opening of the sheath.

On $4^{\text {th }}$ October the sheath was still more swollen and reddened, and there was a slight discharge from it. It was now impossible to expose the penis. During the following ten days the swelling persisted, while the small sore which made its appearance on 3 rd October continued to spread as a red ulcerating surface around the opening of the sheath.

On I5th October two small abscesses were found to have formed on the prepuce near the primary sore, and these on the following day had become converted into shallow ulcers. On the I6th a third small abscess had formed. On the $\mathrm{I} 7 \mathrm{th}$ all the ulcers had increased in extent, and were covered with brownish crusts. After this date the sores began to heal, and had disappeared in about a fortnight.

On I4th October an attempt was made to transmit the disease by means of cotton wool and discharge from this wether to another wether and a ewe, but neither of these animals became infected. An attempt to isolate from the sores an organism capable of inducing the disease also failed, and the experiments thus came to an end.

It is scarcely possible that this can be a disease of common occurrence among sheep, as it is not one that can escape notice, and it must long ere this have attracted attention if it had been common. If the circumstances were favourable, the disease is evidently one that might spread indefinitely; but, since it seems to run a comparatively rapid course, and always ends in recovery, a flock infected with it one season would probably have become clean by the following season. There may, however, be exceptions to this rule, the disease being continued from one season to the next, either by a ram or a ewe that has not made a complete recovery. At anyrate, it would appear to be a not altogether needless precaution to see that newly-purchased rams are free from any sign of the disease.

\title{
A CASE OF EPIZOOTIC LYMPHANGITIS.
}

\author{
By J. M'Fadyean, Royal Veterinary College, London.
}

History teaches us that great wars have always contributed to the dissemination of disease, both among human beings and among the lower animals, and it is already evident that the recent campaign in South Africa has conformed to this rule. By that agency glanders was spread throughout the whole of the Transvaal and Orange River Colonies, as well as in Cape Colony and Natal. That was only what might have been expected. What was not foreseen was that the 